\title{
OBTENÇÃO DE BIOCARVÕES ATIVADOS A PARTIR DE RESÍDUOS DE BARU (Dipteryx alata Vog) E SUA APLICAÇÃO COMO ADSORVENTES
}

Obtaining activated biochar from baru biomass waste (Dipteryx alata Vog) and its application as adsorbents

Obtención de biocarvas activadas del desecho de biomasa de baru (Dipteryx alata Vog) y su aplicación como adsorbentes

Yara Karla de Salles Nemet ${ }^{* 1}$, Fábio Eduardo Nemet ${ }^{* 2}$, Stéfanie Rhoden Gregório*3, Magale Karine Diel Rambo*4

${ }^{1,4}$ Universidade Federal do Tocantins, Palmas-TO, Brasil.

${ }^{2}$ Universidade do Norte do Paraná, Palmas-TO, Brasil.

${ }^{3}$ Escola Técnica Residência Educação, Palmas-TO, Brasil.

Correspondência: Universidade Federal do Tocantins, Av. NS 15, 109 Norte, Palmas,Tocantins, Brasil. CEP:77.010-090. e-mail: yaravideira@gmail.com

Artigo recebido em 02/07/2020 aprovado em 26/10/2020 publicado em 17/03/2021.

\section{RESUMO}

A biomassa vegetal é uma mistura complexa constituída em especial por celulose, hemicelulose e lignina e é de grande importância como fonte de recursos renováveis. Neste trabalho, realizou-se a produção e caracterização dos biocarvões ativados do endocarpo e mesocarpo de baru, a fim de avaliar seu potencial como adsorvente em soluções de carboidratos. Para tal, os resíduos brutos, bem como os resíduos submetidos a processos de hidrólise ácida, seguiram por um processo de pirólise lenta, para a obtenção dos biocarvões. Em seguida, estes foram ativados quimicamente utilizando-se o cloreto de zinco como reagente de ativação. As amostras de biocarvões ativados foram caracterizadas com análise aproximada, análise superficial e adsorção de carboidratos. Os biocarvões ativados das amostras brutas e hidrolisadas da fração endocarpo do baru apresentaram valores significativos maiores $\left(>600 \mathrm{~m}^{2} / \mathrm{g}\right)$ para área superficial quando comparados com o carvão ativado comercial, o que permite que seja utilizado como adsorvente. O percentual de adsorção de carboidratos encontrado nos carvões de baru (independente da fração e processo) foram menores que a adsorção registrada para o carvão ativado comercial, o que é desejável nas indústrias. Com base nesses resultados, foi possível concluir que os biocarvões de baru apresentam elevado potencial de aplicação como adsorventes.

Palavras-chave: Hidrólise; Ativação; Carvão ativado.

\begin{abstract}
Vegetable biomass is a complex mixture consisting in particular of cellulose, hemicellulose and lignin and is of great importance as a source of renewable resources. In this work, the production and characterization of activated biocarbons of the endocarp and mesocarp of baru was carried out, in order to evaluate its potential as an adsorbent. For this, the crude residues, as well as the residues submitted to acid hydrolysis processes, followed a slow pyrolysis process, in order to obtain biocarbons. Then, they were chemically activated using zinc chloride as the activation reagent. The samples of activated biocarbons were characterized with approximate analysis, surface analysis and carbohydrate adsorption. The activated biocarbons of the crude and hydrolyzed samples of the barocarbon fraction showed significantly higher values ( $>600 \mathrm{~m} 2 / \mathrm{g}$ ) for surface area when compared with commercial activated carbon, which allows it to be used as an adsorbent. The percentage of carbohydrate adsorption found on baru coals (regardless of fraction and process) was lower than the adsorption recorded for commercial activated carbon, which is desirable in industries. Based on these results, it was possible to conclude that baru biocarbons have high application potential as adsorbents.
\end{abstract}

Keywords: Hydrolysis; Activation; Activated charcoal. 


\section{RESUMEN}

La biomasa vegetal es una mezcla compleja formada en particular por celulosa, hemicelulosa y lignina y es de gran importancia como fuente de recursos renovables. En este trabajo se realizó la producción y caracterización de biocarbonos activados del endocarpio y mesocarpio de baru, con el fin de evaluar su potencial como adsorbente. Para ello, los residuos crudos, así como los residuos sometidos a procesos de hidrólisis ácida, siguieron un proceso de pirólisis lento, con el fin de obtener biocarbonos. Luego, se activaron químicamente utilizando cloruro de zinc como reactivo de activación. Las muestras de biocarbonos activados se caracterizaron con análisis aproximado, análisis de superficie y adsorción de carbohidratos. Los biocarbonos activados de las muestras crudas e hidrolizadas de la fracción del endocarpio de baru mostraron valores significativamente más altos (>600 m2 / g) para el área superficial en comparación con el carbón activado comercial, lo que permite su uso como adsorbente. El porcentaje de adsorción de carbohidratos que se encuentra en los carbones de baru (independientemente de la fracción y el proceso) fue menor que la adsorción registrada para el carbón activado comercial, que es deseable en las industrias. Con base en estos resultados, fue posible concluir que los biocarbonos de baru tienen un alto potencial de aplicación como adsorbentes. Descriptores: Hidrólisis; Activación; Carbón activado.

\section{INTRODUÇÃO}

Devido ao crescimento exacerbado da população e a exploração indiscriminada dos recursos naturais, observa-se uma clara tendência de esgotamento destes recursos. Com isso, parece claro que a biomassa produzida a partir de resíduos será, num futuro muito próximo, a principal fonte de recursos para obtenção de energia e de adjuvantes tecnológicos (RAMBO et al., 2020).

As espécies de plantas nativas do cerrado têm se destacado por apresentar potencial com forte apelo social e econômico, constituindo matéria-prima disponível e renovável para obtenção de bioprodutos de valor agregado (LANCEFIELD et al., 2017; BLAMEY et al., 2017).

O baru (Dipteryx alata Vog.) é um fruto nativo do cerrado brasileiro pertencente à família Faboideae. É muito utilizado devido à sua diversidade de aplicação, como uso alimentar, madeireiro, medicinal, industrial, paisagístico e na recuperação de áreas degradadas. A grande adaptabilidade do baru resulta em alta produtividade, com frutos e sementes de boa qualidade (FERREIRA et al., 2018).

O fruto apresenta uma semente comestível, comumente conhecida como amêndoa, um mesocarpo fibroso e adocicado e um endocarpo lenhoso na parte interna (TAKEMOTO et al., 2001; SANO et al., 2004; BENTO et al., 2014). Existe o interesse econômico e ambiental, pois ao se retirar a amêndoa, as cascas residuais (mesocarpo e o endocarpo) são descartadas diretamente no meio ambiente.

Apesar de serem úteis como matéria orgânica ao solo, a ideia de utilizar esses resíduos em biorrefinarias se torna mais útil, pois produtos de grande valor comercial podem ser obtidos, gerando mais renda do que apenas aproveitando esse resíduo em lavouras (RAMBO et al., 2020).

Devido às características físico-químicas dos resíduos de baru, o objetivo do trabalho consiste em aproveitar essa biomassa por um processo termoquímico, conhecido como pirólise, para obter produtos de grande valor agregado como biocarvões ativados, com possível potencial de uso como adsorventes em soluções de açúcares.

\section{MATERIAIS E MÉTODOS}

\section{Matéria prima}

Todos os experimentos foram realizados em duplicata no Laboratório Multiusuário de Análises Físicas e Químicas do solo, ar e água da Universidade Federal do Tocantins (UFT) e no Laboratório de Inovação em Aproveitamento de Resíduos e Sustentabilidade do Instituto Federal do Tocantins (IFTO).

Os frutos do baru (Dipteryx alata Vog.) utilizados neste trabalho foram cedidos por agricultores 
de Porangatu, estado de Goiás, Brasil, em outubro de 2017, e foram armazenados em embalagens plásticas de polietileno em temperatura ambiente.

As amêndoas do baru foram retiradas manualmente como auxílio de uma faca. Os frutos foram secos em estufa com circulação de ar (Solid Steel SSD 110L) a $105{ }^{\circ} \mathrm{C}$ por $12 \mathrm{~h}$, e o mesocarpo e o endocarpo foram separados manualmente. Após a separação, o mesocarpo e endocarpo do baru foram triturados em moinho (moinho de tipo Willey, modelo star FT 50, marca Fortenox), na sequência foram peneirados até o tamanho de partículas de 45 mesh $(0,35 \mathrm{~mm})$ e armazenadas em frascos de vidros herméticos em temperatura ambiente.

\section{Hidrólise ácida}

As amostras brutas foram submetidas a um processo de hidrólise ácida de dois estágios (NREL/TP510-42619, 2011). No primeiro passo, a amostra e o ácido sulfúrico a $72 \%$ (3 mL) foram transferidos para um banho-maria, mantidos a $60{ }^{\circ} \mathrm{C}$ durante um período de $1 \mathrm{~h}$, e agitados a cada $10 \mathrm{~min}$. $\mathrm{Na}$ segunda etapa, foram adicionados $84 \mathrm{~mL}$ de água e a amostra foi transferida para autoclave (autoclave vertical, Phoenix) por $1 \mathrm{~h}$ a $120^{\circ} \mathrm{C}$. Os tubos de pressão foram filtrados em cadinhos de porosidade média (10 a $15 \mu \mathrm{m}$ ) utilizando uma bomba à vácuo (LT 65, Limatec, acoplado).

Ao final do processo de hidrólise, o resíduo sólido, foi utilizado para pirólise, com o intuito de avaliar o potencial desse resíduo ácido como biocarvão.

\section{Pirólise}

As amostras brutas, bem como os resíduos sólidos oriundos da hidrólise ( $30 \mathrm{~g}$ ) foram submetidos separadamente a um processo de pirólise lenta em um reator de leito fixo, de aço inox, tubular Pyrex a $500^{\circ} \mathrm{C}$ por $30 \mathrm{~min}$, a uma taxa de $\sim 10 \mathrm{~K} / \mathrm{min}$. O reator foi aquecido por forno bipartido reclinável (marca FLYEVER, modelo FE50RPN e linha 05/50), sendo operado em regime de batelada. O gás de arraste empregado na reação foi o vapor de água aquecido entre $133^{\circ} \mathrm{C}$ e $139^{\circ} \mathrm{C}$ em autoclave. Após a reação e o resfriamento da unidade de pirólise, todos os produtos do processo (líquido e sólido) foram coletados, pesados e calculados os rendimentos. O material sólido foi recuperado diretamente do reator e os líquidos pirolíticos foram coletados após o sistema de condensação dos vapores em funil de separação de fases (PEDROZA, 2017).

\section{Análise aproximada}

$\mathrm{O}$ teor de umidade foi determinado de acordo com as normas de ASTM-D3174 (2004).

$\mathrm{O}$ conteúdo de matéria volátil (MV) foi determinado em mufla a $550{ }^{\circ} \mathrm{C}$ por 8 minutos. A amostra foi retirada e colocada em dessecador para ser resfriada, sendo finalmente pesada e seu teor de MV calculado (ASTM-D3175, 2007).

$\mathrm{O}$ teor de cinzas (CZ) foi determinado em mufla por um período de $12 \mathrm{~h}$ a $550^{\circ} \mathrm{C}$. A determinação de cinzas é expressa como porcentagem de resíduo (material orgânico) que permanece após a oxidação a $550{ }^{\circ} \mathrm{C}$ (ASTM-D3174, 2004).

O teor de Carbono fixo (CF) é uma medida indireta e foi calculado pela Equação abaixo.

$$
\mathrm{CF}(\%)=100-(\mathrm{CZ}+\mathrm{MV})
$$

E o teor de Carbono (C) foi analisado em um analisador Elementar de Carbono (C), Nitrogênio(N), Hidrogênio (H) e Enxofre (S) (Vario MACRO Cube Hanau, Alemanha). 


\section{Área superficial}

As amostras de biocarvões e biocarvões ativados foram analisadas em equipamento ASAP (Micromeritics, modelo ASAP 2010, Chemisorption) e aquecidas sob vácuo a fim de remover umidade, e posteriormente, foram resfriadas e expostas ao gás de análise em uma série de pressões precisamente controladas, sob temperatura de tratamento de 30-350 ${ }^{\circ} \mathrm{C}$ (COSTA, FURMANSKI e DOMINGUINI, 2015).

\section{Ativação química}

As amostras dos biocarvões (bruta e hidrolisada) foram imersas em uma solução de cloreto de zinco $-\mathrm{ZnCl}_{2}$, na concentração de $10 \% \mathrm{~m} / \mathrm{v}$ e na proporção de 1:5 (carvão:solução, massa:volume). A escolha desse reagente de ativação se deu pelo baixo custo e pela disponibilidade em nosso laboratório.

A amostra foi imersa em solução e o sistema foi coberto com um filme plástico, permanecendo em repouso por $24 \mathrm{~h}$. Decorrido este tempo, a amostra foi lavada com água destilada e seca em estufa a $110 \pm 5$ ${ }^{\circ} \mathrm{C}$.

O material lavado foi colocado em um cadinho de cordierita, fechado com lã de rocha e uma placa de cordierita, e pirolisado novamente por tratamento térmico, em forno tipo vertical (Jung 815), a $600 \pm 5$ ${ }^{\circ} \mathrm{C}$, a uma taxa de $10{ }^{\circ} \mathrm{C} \mathrm{min}{ }^{-1}$, sendo mantido nessa temperatura durante $2 \mathrm{~h}$. O carvão ativado foi lavado com uma solução de ácido clorídrico - $\mathrm{HCl}$, a $2 \mathrm{~mol} \cdot \mathrm{L}^{-}$ 1, para remoção e desobstrução dos poros. Ao final do processo, a amostra foi seca em estufa a $110 \pm 5^{\circ} \mathrm{C}$ por 24 h, e denominada de carvão ativado com tratamento químico (COSTA, FURMANSKI e DOMINGUINI, 2015).

\section{Adsorção carboidratos}

Os biocarvões ativados foram avaliados quanto à adsorção de carboidratos. Para o teste de adsorção (ESSIG et al., 1988) adicionou-se $50 \mathrm{~mL}$ de solução de carboidratos $50 \%$ sobre $0,50 \mathrm{~g}$ de carvão o mantendo em banho maria durante $15 \mathrm{~min}$. As misturas foram centrifugadas (10.000 rpm) e filtradas após este período. As soluções filtradas foram diluídas em 250 $\mathrm{mg} \mathrm{L}^{-1}$, e foram adicionados $0,60 \mathrm{~mL}$ das soluções de fenol 0,5\% e 3,00 $\mathrm{mL}$ de ácido sulfúrico concentrado a 0,60 mL nas soluções diluídas. Procedeu-se com análise em ultravioleta em comprimento de onda de 49 nm mensurando-se o teor de carboidratos (TC).

\section{RESULTADOS E DISCUSSÃO}

A pirólise das amostras brutas produziu grandes quantidades de biocarvão do mesocarpo e endocarpo do baru, com rendimentos de 50,30\% e $49,10 \%$, respectivamente. Já as amostras hidrolisadas quando pirolisadas forneceram resultados bem semelhantes ao da pirólise de amostra bruta, com $48,5 \%$ de mesocarpo e 47,9\% de endocarpo.

Nas tabela 1 e 2 são apresentados os valores médios (das duplicatas) com os seus respectivos desvios padrões obtidos dos biocarvões brutos e após o processo de ativação, respectivamente. Os coeficientes de variação ficaram todos abaixo de 0,06\%, demonstrando assim a boa precisão dos dados.

Os teores de MV e de CF sofrem variação com a velocidade do processo, sendo que que o aumento na taxa de aquecimento promove a diminuição, no teor de MV e o aumento no teor de CF. O teor de cinzas, por outro lado, tende a aumentar, pois é dependente da quantidade de matéria mineral presente na biomassa. Dessa forma, os menor teores de cinzas e os maiores teores de MV sugerem que esses biocarvões são mais ricos em materiais voláteis (Vella et al., 1989) . 
O teor de umidade foi baixo para todos os resultados $(<4,6 \%)$.

Na tabela 3 é possível verificar os valores médios com seus respectivos desvios padrões, de área superficial (BET e LANGMUIR) e volume de microporos dos biocarvões brutos e ativados.

De acordo com as diretrizes para certificação de biochars, o mínimo recomendável de área superficial é $>150 \mathrm{~m}^{2} / \mathrm{g}$ para ser considerado um bom carvão (IBI, 2015; NIZAMUDDIN et al., 2016). Os biocarvões ativados das amostras brutas e hidrolisadas (BAAB e BAAH) do endocarpo do baru apresentaram valores de área superficial (BET e Langmuir) significativos (> $608 \mathrm{~m}^{2} / \mathrm{g}$ ) em relação ao carvão ativado comercial (CAC). Provavelmente a natureza da fração endocarpo, com teores de cinzas menores que a fração mesocarpo (Tabela 1 e 2), levou a valores maiores de área superficial. Segundo Bruum et al. (2008) o baixo teor de cinzas é um fator positivo para produção de carvão, visto que a matéria mineral, devido ao caráter hidrofílico, promove a adsorção de água, competindo com outros compostos de interesse. Pode-se observar ainda o aumento no teor de carbono nas frações de endocarpo (Tabelas 1 e 2), devido à eliminação de hidrogênio e de oxigênio no processo de pirólise, o que eleva a área superficial.

Todos os carvões ativados contêm micro, meso e macroporos em sua estrutura, mas a proporção varia de acordo com a matéria-prima e o processo de fabricação utilizado. A maioria dos carvões obtidos nesse trabalho, apresentaram micro e mesoporos (>85\%). O carvão ativado BAAH apresentou em sua maioria mesoporos, associados com a maior área superficial BET encontrada.

Valores significativos de área superficial, baixo teor de cinzas $(<0,50 \%)$ e elevado teor de carbono ( $>90 \%$ ) comprovam a possibilidade de uso do endocarpo do baru para a produção de carvão ativado. Costa, Furmanski e Dominguini (2015) também encontraram a possibilidade do uso das cascas de nozes para produção de carvão ativado com elevada área superficial (acima de $600 \mathrm{~m}^{2} / \mathrm{g}$ ), baixo teor de cinza (6,7a 7,2 \%) e elevado teor de carbono (acima de 78\%). Boligon (2015) ativou o biocarvão obtido da borra de café solúvel, no qual a ativação com $\mathrm{KOH}$ aumentou 30,23 vezes $\left(2541,13 \mathrm{~m}^{2} / \mathrm{g}\right)$ em relação ao sem ativar e 11,87 vezes de aumento $\left(997,50 \mathrm{~m}^{2} / \mathrm{g}\right)$ ativado com $\mathrm{K}_{2} \mathrm{CO}_{3}$.

Após o processo de ativação, comparou-se a capacidade de adsorção destes biocarvões ativados, e o carvão ativado comercial (CAC) encontrado por Cardoso (2004) (Tabela 3).

Para o carvão ativo comercial o percentual de redução foi de $14,12 \%$, enquanto que para os biocarvões ativados obtidos no presente estudo, os percentuais foram todos inferiores a $13,15 \%$. Isto significa que estes adsorvem uma menor quantidade de carboidratos em relação ao carvão ativo comercial, o que é desejável, uma vez que o ideal é não adsorver os açúcares (glicose). 
Tabela 1. Estatística descritiva (média, desvio padrão e coeficiente de variação) da análise aproximada dos biocarvões brutos.

\begin{tabular}{c|l|l|l|l}
\hline $\begin{array}{c}\text { Análises } \\
(\boldsymbol{\%})\end{array}$ & \multicolumn{1}{|c|}{$\boldsymbol{B A B}-\boldsymbol{M}$} & \multicolumn{1}{|c|}{$\boldsymbol{B A B}-\boldsymbol{E}$} & $\boldsymbol{B A H}-\boldsymbol{M}$ & $\boldsymbol{B A H}-\boldsymbol{E}$ \\
\hline Umidade & $2,52 \pm 0,05^{(0,02)^{*}}$ & $4,25 \pm 0,07^{(0,02)}$ & $2,87 \pm 0,07^{(0,02)}$ & $4,62 \pm 0,09^{(0,02)}$ \\
\hline Cinzas & $0,47 \pm 0,02^{(0,04)}$ & $0,35 \pm 0,02^{(0,06)}$ & $0,55 \pm 0,02^{(0,04)}$ & $0,49 \pm 0,02^{(0,04)}$ \\
\hline MV & $25,5 \pm 0,01^{(0,00)}$ & $28,2 \pm 0,00^{(0)}$ & $24,0 \pm 0,0^{(0,01)}$ & $26,5 \pm 0,01^{(0,0)}$ \\
\hline C & $72,0 \pm 0,10^{(0,001)}$ & $75,05 \pm 0,17^{(0,002)}$ & $81,9 \pm 0,84^{(0,0)}$ & $83,6 \pm 0,36^{(0,00)}$ \\
\hline CF & $74,2 \pm 0,01^{(0,00)}$ & $71,5 \pm 0,01^{(0,00)}$ & $75,0 \pm 0,01^{(0,0)}$ & $72,8 \pm 0,01^{(0,00)}$ \\
\hline
\end{tabular}

Legenda: BAB-M: Biocarvão de Amostra Bruta do Mesocarpo; BAB-E: Biocarvão de Amostra Bruta do Endocarpo; BAH-M: Biocarvão de Amostra Hidrolisada do Mesocarpo; BAH-E: Biocarvão de Amostra Hidrolisada do Endocarpo

Tabela 2. Estatística descritiva (média, desvio padrão e coeficiente de variação) da análise aproximada dos biocarvões ativados.

\begin{tabular}{c|l|l|l|l}
\hline $\begin{array}{c}\text { Análises } \\
(\boldsymbol{\%})\end{array}$ & BAAB-M & BAAB-E & BAAH-M & BAAH-E \\
\hline Umidade & $1,98 \pm 0,04^{(0,02)^{*}}$ & $3,90 \pm 0,05^{(0,01)}$ & $2,51 \pm 0,02^{(0,00)}$ & $3,52 \pm 0,07^{(0,02)}$ \\
\hline Cinzas & $0,40 \pm 0,{ }^{01(0,00)}$ & $0,29 \pm 0,05^{(0,17)}$ & $0,50 \pm 0,01^{(0,02)}$ & $0,41 \pm 0,05^{(0,12)}$ \\
\hline MV & $19,90 \pm 0,02^{(0,00)}$ & $20,1 \pm 0,01^{(0.00)}$ & $19,5 \pm 0,01^{(0,00)}$ & $20,50 \pm 0,01^{(0,00)}$ \\
\hline $\mathrm{C}$ & $87,50 \pm 0,20^{(0,00)}$ & $91,1 \pm 0,15^{(0.00)}$ & $88,5 \pm 0,90^{(0,01)}$ & $96,10 \pm 0,20^{(0,00)}$ \\
\hline$C F$ & $79,70 \pm 0,01^{(0,00)}$ & $89,56 \pm 0,01^{(0,00)}$ & $80,0 \pm 0,01^{(0,00)}$ & $91,09 \pm 0,01^{(0,00)}$ \\
\hline
\end{tabular}

Legenda:BAAB-M: Biocarvão Ativado de Amostra Bruta do Mesocarpo; BAAB-E:

Biocarvão Ativado de Amostra Bruta do Endocarpo; BAAH-M: Biocarvão Ativado de Amostra Hidrolisada do Mesocarpo; BAAH-E: Biocarvão Ativado de Amostra Hidrolisada do Endocarpo

*Valores do coeficiente de variação amostral (\%).

Tabela 3. Área Superficial dos biocarvões brutos e biocarvões ativados.

\begin{tabular}{c|c|c|c}
\hline CARVÃo & $\begin{array}{c}\text { BET } \\
\left(\mathbf{m}^{2} / \mathbf{g}\right)\end{array}$ & $\begin{array}{c}\text { Langmuir } \\
\left(\mathbf{m}^{2} / \mathbf{g}\right)\end{array}$ & $\begin{array}{c}\text { Poros } \\
\left(\mathbf{c m}^{3} / \mathbf{g}\right)\end{array}$ \\
\hline BAB-M & $1,92 \pm 0,1328$ & $2,67 \pm 0,158$ & 0,00041 \\
\hline BAAB-M & $6,74 \pm 0,1248$ & $10,68 \pm 0,105$ & 0,00164 \\
\hline BAB-E & $43,82 \pm 1,0721$ & $58,83 \pm 0,542$ & 0,01387 \\
\hline BAAB-E & $630,05 \pm 1,0227$ & $608,12 \pm 0,505$ & 0,02775 \\
\hline BAH-M & $0,13 \pm 0,0273$ & $0,162 \pm 0,029$ & 0,00117 \\
\hline BAAH-M & $4,37 \pm 0,01545$ & $5,50 \pm 0,129$ & 0,03547 \\
\hline BAH-E & $126,76 \pm 2,2521$ & $169,07 \pm 0,521$ & 0,04186 \\
\hline BAAH-E & $887,34 \pm 1,1227$ & $929,89 \pm 0,305$ & 0,33489 \\
\hline *CAC & 612,00 & - & \\
\hline
\end{tabular}

Legenda: BAB-M: Biocarvão de Amostra Bruta do Mesocarpo; BAB-E: Biocarvão de Amostra Bruta do

Endocarpo; BAH-M: Biocarvão de Amostra Hidrolisada do Mesocarpo; BAH-E: Biocarvão de Amostra

Hidrolisada do Endocarpo; BAAB-M: Biocarvão Ativado de Amostra Bruta do Mesocarpo; BAAB-E: Biocarvão Ativado de Amostra Bruta do Endocarpo; BAAH-M:

Biocarvão Ativado de Amostra Hidrolisada do Mesocarpo;

BAAH-E: Biocarvão Ativado de Amostra Hidrolisada do Endocarpo; CAC: Carvão Ativado Comercial.
Tabela 4. Adsorção de carboidratos

\begin{tabular}{c|c|c|c}
\hline & $\begin{array}{c}\text { Abs. } \\
(\boldsymbol{\lambda}=\mathbf{4 9 0} \mathbf{~ n m})\end{array}$ & TC & $\begin{array}{c}\text { Redução } \\
(\mathbf{\%})\end{array}$ \\
\hline Padrão & 0,69 & & \\
\hline $\begin{array}{c}\text { Solução } \\
\text { Xarope }\end{array}$ & 0,87 & 14,18 & \\
\hline BAB-M & 0,75 & 12,23 & $13,76 \%$ \\
\hline BAAB-M & 0,76 & 11,95 & $13,15 \%$ \\
\hline BAB-E & 0,78 & 12,72 & $10,31 \%$ \\
\hline BAAB-E & 0,80 & 14,45 & $9,09 \%$ \\
\hline BAH-M & 0,77 & 12,55 & $11.46 \%$ \\
\hline BAAH-M & 0,78 & 12,95 & $10,85 \%$ \\
\hline BAH-E & 0,80 & 13,04 & $8,01 \%$ \\
\hline BAAH-E & 0,82 & 15,07 & $6,79 \%$ \\
\hline CAC* & 0,73 & 13,68 & $14,12 \%$ \\
\hline
\end{tabular}

Legenda: TC: Teor de Carboidratos

\section{CONCLUSÃO}

O uso de resíduos de biomassa do mesocarpo e endocarpo do baru mostrou-se uma alternativa muito atraente, uma vez que sua caracterização físicoquímica apresentou composição favorável para a obtenção de biocarvões.

Os biocarvões ativados (BAAB e BAAH) da fração do endocarpo apresentaram valores 
satisfatórios, para área superficial BET e Langmuir, além de terem sido comprovados como bons adsorventes para soluções de carboidratos.

Todos os autores declararam não haver qualquer potencial conflito de interesses referente a este artigo.

\section{REFERÊNCIAS}

ASTM D 3174-04. Standard Practices for Infrared Multivariate Quantitative Analysis; 2004.

ASTM D 3175-07. Standard Practices for Infrared Multivariate Quantitative Analysis; 2007.

BENTO, A.P.N; COMINETTI, C; FILHO, A. S; NAVES, M. M. V. Baru almond improves lipid profile in mildly hypercholesterolemic subjects: A randomized, controlled, crossover study. Nutrition, Metabolism \& Cardiovascular Diseases, v. 24, p. 1330-1336, 2014.

BLAMEY, J. M., FISCHER, F., MEYER, H. P., SARMIENTO, F., ZINN, M. Enzymatic biocatalysis in chemical transformations: a promising and emerging field in green chemistry practice. Biotechnology of Microbial Enzymes, Cap.14, p. 347-403, 2017.

BOLIGON, J. Produção e caracterização de carvão ativado a partir da borra de café solúvel.Tese de Mestrado. Londrina, 2015.

BRUUM. S.S; Bianchi, M.L; Silva, V.L; Gonçalves, M; Guerreiro, M.C; Oliveira, O. P. Preparation and characterization of activated carbon produced from coffee waste. Química Nova, vol.31 p. 10481052, 2008.

CARDOSO, A.L. Pirólise Lenta de Serragem de Eucalipto para produção de bio-óleo e carvão. Dissertação mestrado em Química Analítica, 68f. 2004.

COSTA, P.D; FURMANSKI, L.M; DOMINGUINI,L. Produção, caracterização e aplicação de carvão ativado de casca de Nozes para adsorção de azul de metileno.Revista Virtual Química, v. 7, n. 4, p. 12721285, 2015.

ESSIG, M; LOWARY, G. N; RICHARDS, E; SCHENCK, E. Research in thermo chemical biomass conversion. Elsevier Applied Science, 1988.
FERREIRA, C.M; GABRIEL, G. H; NEPOMUCENO, L; CRUZ, V. S. ARAUJO, E. G. Caracterização botânica e cadeia produtiva da espécie Dipteryx Alata vogel. Enciclopédia Biosfera, Centro Científico Conhecer - Goiânia, v. 15, n. 28, 2018.

IBI - International Biochar Initiative. Standardized Product Definition and Product Testing Guidelines for Biochar That Is Used in Soil. Product Definition and Specification Standards, 2015. Disponível: https://www.biochar-

international.org/wpcontent/uploads/2018/04/IBI_Bio char_Standards_V2.1_Final.pdf. Acesso em: Outubro de 2018.

LANCEFIELD, C. S., PANOVIC, I., DEUSS, P. J., BARTA, K., WESTWOOD, N. J. Pre-treatment of lignocellulosic feedstocks using biorenewable alcohols: towards complete biomass valorisation. Green Chemistry, v. 19, n. 1, p. 202214, 2017.

NREL/TP-510-42619: Determination of Extractives in Biomass. Biomass Analysis Technology Team Laboratory Analytical Procedure, National Renewable Energy Lab, 2011.

PEDROZA, M. M. Aproveitamento energético de resíduos sólidos urbanos em processos de pirólise. Revista Brasileira de Energias Renováveis, v. 6, n. 2, p. 184-207, 2017.

RAMBO, M. K. D; RAMBO, M. C. D; MELO, P. M; OLIVEIRA, N. M. L; NEMET, Y. K. S; SCAPIN, E; VIANA, G. C. C; BERTUOL, D. A. Sustainability of biorefinery processes based on Baru biomass waste. Journal of the Brazilian Chemical Society, v. 31, n. 2, p. 273-279, 2020.

SANO, S. M; RIBEIRO, J. F; BRITO, M. A;Baru: biologia e uso. Embrapa Cerrados-Documentos (INFOTECA-E), 2004.

TAKEMOTO E.; OKADA I. Composição química da semente e do óleo de baru (Dipteryx alata Vog.) nativo do Município de Pirenópolis, Estado de Goiás. Revista Instituto Adolfo Lutz, v. 60, n. 2, p. 113 117, 2001.

VELLA, M. M. C. F.; VALENTE, B. R. V.; LELLES, J. G. Influência da velocidade de carbonização da madeira nos rendimentos e nas propriedades do carvão Produzido. IPEF, Piracicaba, v. 41/42, p. 64-76, 1989. 